Rev Inv Vet Perú 2004; 15 (1): 8-12

\title{
CLORURO DE BENZALCONIO EN EL TRATAMIENTO DE LA DERMATOMICOSIS CAUSADA POR Trichophyton sp. EN EL CUY (Cavia cobayo)
}

\author{
Sandra Bezada Q. ${ }^{1}$, Norma Noé M. ${ }^{2}$, Vilma Béjar C. ${ }^{3}$ y Juan Muscari G. ${ }^{4}$
}

\section{Abstract}

The efficacy of benzalkonium chloride for the treatment of dermatomicosis caused by Trichophyton sp. in guinea pig (Cavia cobayo) was evaluated in 200 guinea pigs of two months old, that showed typical clinical signs of dermatomicosis. Hair samples and skin grudges were taken for direct exam and for in vitro culture in Dermatophytes Test Medium and Mycobiotic. Skin biopsies for pathobiology were prepared. The guinea pig were divided in groups A and B of 100 animals each. Group A was treated with $0.1 \%$ aqueous benzalkonium chloride solution, whereas group B was treated with water as placebo. All samples were positive to media culture by $3^{\text {rd }}$ to $7^{\text {th }}$ day and Trichophyton mentagrophytes was isolated. Sixty percent of the samples were positive to direct exam. Histological study showed mild hyperkeratosis. Healing of lesions and hair growth were observed in all treated guinea pigs by the end of $4{ }^{\text {th }}$ week. The study showed that a single application of $0.1 \%$ aqueous benzalkonium chloride solution was effective for topical treatment on guinea pig dermatomycosis.

Key words: benzalkonium chloride, dermatomycosis, guinea pig, treatment

\section{RESUMEN}

Se evaluó la eficacia del cloruro de benzalconio en el tratamiento de la dermatomicosis causada por Trichophyton sp. en el cuy (Cavia cobayo). Se utilizó 200 cuyes de 2 meses de edad que presentaban signos clínicos de dermatomicosis. Los cuyes fueron divididos al azar en dos grupos (A y B) similares. Al grupo A se le aplicó una solución acuosa de cloruro de benzalconio al $0.1 \%$ como único tratamiento y en el grupo B se empleó agua como placebo. Previo al tratamiento, se tomaron muestras de pelos y escamas de piel para examen directo y cultivo en los medios Dermatophytes Test Medium (DTM) y Mycobiotic, así como biopsias de piel para estudio histológico. Todas las muestras resultaron positivas a hongos entre el $3^{\circ}$ y $7^{\circ}$ día, tipificándose la especie Trichophyton mentagrophytes con la ayuda de microcultivos y lectura en agar urea. El $60 \%$ de las muestras fueron positivas al examen directo. El estudio histológico mostró hiperqueratosis

\footnotetext{
${ }^{1}$ Práctica privada. E-mail: sbezada98@hotmail.com

${ }^{2}$ Laboratorio de Medicina Veterinaria Preventiva, FMV-UNMSM

${ }^{3}$ Instituto de Medicina Tropical "DAC", UNMSM

${ }^{4}$ Instituto Nacional de Investigación Agraria (INIA)
} 
ligera. El 100\% de los cuyes del grupo A mostró curación clínica con crecimiento de pelo al finalizar la $4^{\mathrm{a}}$ semana post-tratamiento. Se concluye que una sola aplicación de cloruro de benzalconio al $0.1 \%$ en solución es eficaz para el tratamiento topical de la dermatomicosis causada por Trichophyton mentagrophytes; lográndose una eficacia del $70 \%$ en la tercera semana post-tratamiento, sin que cause daño a la piel y sin ser afectada por la presencia de materia orgánica.

Palabras clave: cloruro de benzalconio, dermatomicosis, cuy, tratamiento

\section{INTRODUCCIÓN}

Las dermatomicosis son enfermedades producidas por hongos de los géneros Trichophyton, Microsporum y Epidermophyton (este último género es exclusivo de humanos) que infestan tanto al hombre como a los animales (Acha y Szyfres, 1992; Arenas, 1993; Beck, 1998; Burke, 1994; Schilling, 1984).

El cuy es una especie nativa adecuada para la crianza doméstica y semi-comercial, que por la calidad de su carne, precocidad, rusticidad y prolificidad, constituye una importante fuente de alimentación y de ingreso económico (Bustamante, 1993; Celis, 1998). Las técnicas actuales de crianza bajo las cuales se reproducen estos animales los hacen susceptibles de contraer enfermedades que antes eran de escasa presentación en esta especie. Tal es el caso de la dermatomicosis, enfermedad que afecta a grupos enteros (Burke, 1994; Foil, 1993), sobre todo en recría, llegando a tener una incidencia de 93\% (Celis, 1998).

Esta micosis causa alopecia, prurito, estrés, y en la mayoría de los casos, produce lesiones en la piel, las cuales pueden resultar en infecciones secundarias bacterianas (como las piodermas); además de otorgarle un aspecto indeseable al animal infectado.

El cloruro de benzalconio, compuesto de amonio cuaternario, es utilizado como desinfectante y antiséptico de acción bactericida $\mathrm{y}$ viricida principalmente, sin considerar su propiedad fungicida, específicamente sobre los géneros Trichophyton, Epidermophyton y Candida (Litter, 1992; Merianos, 1991). En el país no se han hecho estudios sobre la efectividad de los compuestos de amonio cuaternario como fungicidas en animales menores de granja, y ya que la dermatomicosis es una enfermedad prevalente en la crianza de cuyes, además de tratarse de una zoonosis potencial, se hace necesario buscar alternativas de tratamiento de fácil aplicación, económicas y de buen resultado. El propósito del presente estudio fue evaluar la eficacia del cloruro de benzalconio en el tratamiento de la dermatomicosis en el cuy, como una alternativa para el control y prevención de esta enfermedad.

\section{Materiales y Métodos}

\section{Animales}

El estudio se realizó en la sede central del Instituto Nacional de Investigación y Extensión Agraria (INIA), La Molina, y el análisis y lectura de las muestras se hizo en el Instituto de Medicina Tropical "DanielAlcides Carrión", UNMSM.

Se trabajó con 200 cuyes de 2 meses de edad, los cuales presentaban lesiones clínicas características de dermatomicosis, descritas como zonas alopécicas cubiertas de escamas, piel engrosada o costras prominentes. Las lesiones se ubicaban alrededor de ojos y nariz principalmente, así como en miembros anteriores, dorso, flancos y vientre. 
Los animales fueron divididos al azar en dos grupos de 100 animales cada uno:

- Grupo A: Animales tratados con una solución acuosa de cloruro de benzalconio al $0.1 \%$. La solución se aplicó una sola vez.

- Grupo B: Animales testigo a los que sólo se aplicó agua potable por única vez.

La aplicación de las soluciones en ambos grupos se realizó mediante frotación, con ayuda de algodón sobre todas las áreas del animal que presentaban las lesiones. Después del tratamiento, los animales fueron colocados en javas por un lapso de 10 minutos y luego fueron devueltos a sus respectivas pozas de crianza. Los resultados se evaluaron y registraron cada semana hasta la desaparición de las lesiones en el grupo A.

\section{Toma de muestras}

Se tomaron muestras de pelos y escamas de piel mediante el método de raspado a 40 animales elegidos al azar del total de ambos grupos. Las muestras fueron sometidas a dos procesos: examen directo y cultivo en agar Dermatophytes Test Medium (DTM) y Mycobiotic. Las muestras se incubaron a $26^{\circ} \mathrm{C}$ durante 15 días. Se empleó también agar urea como prueba diferencial entre especies del género Trichophyton.

En la identificación se tomó en cuenta las características macroscópicas (aspecto, superficie, color, velocidad de desarrollo) y microscópicas (cantidad y forma de las hifas y microconidias).

\section{Resultados y Discusión}

\section{Análisis micológico}

El 60\% de las muestras resultaron positivas al examen directo, observándose infección del tipo ectoendotrix en los pelos. No se observaron hifas en las muestras de escamas. Por otro lado, el $100 \%$ de las muestras resultaron positivas a hongos entre el $3^{\circ}$ y $7^{\circ}$ día de incubación al cultivo en DTM y Mycobiotic, identificándose macroscópicamente como agente causal, al hongo del género Trichophyton. Posteriormente, con el estudio del microcultivo y la hidrólisis de las cepas en agar urea, se tipificó la especie Trichophyton mentagrophytes.

En los cortes histológicos teñidos con hematoxilina-eosina (HE) se observó una ligera hiperqueratosis del estrato córneo, además de una marcada disgregación del tejido conectivo y otros hallazgos compatibles con un proceso inflamatorio agudo.

\section{Tratamiento de los animales}

En el Cuadro 1 se describen los resultados observados al término de cada semana en los grupos A y B, observándose una eficacia del $70 \%$ en la tercera semana post-tratamiento, sin daños en la piel de los animales y sin ser afectados por la presencia de materia orgánica.

Es escaso el material bibliográfico disponible acerca de la utilización y evaluación de compuestos de amonio cuaternario para el tratamiento de esta enfermedad en cuyes; quizás debido al poco interés que se muestra hacia las enfermedades micóticas en esta especie. La constante presencia de esta enfermedad en granjas de cuyes, sobre todo en la época de invierno (Schilling, 1984; Celis, 1998), crearon la urgencia de un tratamiento acorde a nuestra realidad socioeconómica que controle la presentación de un brote. Por esta razón se eligió al cloruro de benzalconio, el cual, a pesar de que la literatura señala que tiene propiedades fungicidas, su uso en veterinaria se limita básicamente a desinfección de objetos inertes, empleándose muy poco como antiséptico de piel (Litter, 1992; Merianos, 1991; Linton et al., 1988). La densidad de crianza de los animales, así como la ingesta de pasto seco maduro en algunas épocas del año, tiene un papel fundamental en el desarrollo de la patogenia de la enfermedad. El mejor método de diagnóstico de 
Cuadro 1. Evolución del tratamiento contra dermatomicosis en cuyes empleando cloruro de benzalconio al $0.1 \%$

\begin{tabular}{|c|c|c|c|c|}
\hline \multirow{2}{*}{ Grupo } & \multicolumn{4}{|c|}{ Semanas post-tratamiento } \\
\hline & Primera semana & Segunda semana & Tercera semana & Cuarta semana \\
\hline A & $\begin{array}{l}\text { Caída de las } \\
\text { costras con inicio } \\
\text { de crecimiento de } \\
\text { pelo en las lesio- } \\
\text { nes que no eran } \\
\text { muy profundas. } \\
\text { Desaparición de } \\
\text { lesiones escamo- } \\
\text { sas en el vientre }\end{array}$ & $\begin{array}{l}\text { El } 45 \% \text { de los } \\
\text { animales se } \\
\text { recuperó. } \\
\text { Aquellos con } \\
\text { múltiples lesiones } \\
\text { mostraron } \\
\text { desecamiento y } \\
\text { caída de las } \\
\text { costras y eritema. }\end{array}$ & $\begin{array}{l}\text { El } 70 \% \text { de los } \\
\text { animales se } \\
\text { recuperó. } \\
\text { Aquellos con } \\
\text { lesiones severas } \\
\text { mostraron costras } \\
\text { secas e inicio del } \\
\text { crecimiento del } \\
\text { pelo. }\end{array}$ & $\begin{array}{l}\text { El } 100 \% \text { de los } \\
\text { animales se } \\
\text { recuperó }\end{array}$ \\
\hline B & Sin cambio & Sin cambio & $\begin{array}{l}\text { Aumento en el } \\
\text { número de las } \\
\text { lesiones con } \\
\text { engrosamiento de } \\
\text { las costras. }\end{array}$ & $\begin{array}{l}\text { Mejoría en el 18\% } \\
\text { de animales con } \\
\text { lesiones leves. }\end{array}$ \\
\hline
\end{tabular}

dermatomicosis es el cultivo en medios de agar específicos para este propósito, a la vez que se identifica al agente patógeno.

\section{Conclusiones}

? El cloruro de benzalconio usado al $0.1 \%$ en solución acuosa tiene acción fungicida contra el dermatofito Trichophyton sp. en la piel del cuy.

? En la concentración utilizada $(0.1 \%)$ es inocuo para el cuy (no es irritante, no es cáustico, ni causa alopecia), y no mancha la piel ni el pelaje.

\section{Agradecimientos}

Los autores agradecen a los Drs. Luis Tabacchi, Víctor Fernández y Francisco Suárez de la FMV-UNMSM por su colaboración para el desarrollo del presente trabajo; $y$ en especial a los Drs. Marcos Lévano y Ramón Zaldívar por sus valiosas sugerencias.

\section{Literatura Citada}

1. Acha, P.; B. Szyfres. 1992. Zoonosis y enfermedades transmisibles comunes al hombre y los animales. $2^{\mathrm{a}}$ ed. Pub. Cient. $N^{\circ}$ 503. OPS. Washington D.C. $989 \mathrm{p}$.

2. Arenas, R. 1993. Micología médica ilustrada: clínica, laboratorio y terapéutica. Ed. Interamericana McGraw-Hill. México DF. 386 p.

3. Beck, W. 1998. Zoophilic dermatophytes as epizoonoses pathogens and their significance to dermatology. Hautarzt: 457-461.

4. Burke, T. 1994. Afecciones cutáneas de roedores, conejos y hurones. En: Kirk y Bonagura. Terapéutica veterinaria de pequeños animales. p 1299-1305. Ed. McGraw-Hill Interamericana. España.

5. Bustamante, J. 1993. Producción de cuyes. Universidad Nacional Mayor de San Marcos. Lima. 259 p. 
6. Celis, E. 1998. Detección de dermatomicosis en cuyes criados en baterías y pozas en la sede central del INIA-Lima. Tesis de Bachillerato. Facultad de Ciencias Agropecuarias. Universidad Nacional Hermilio Valdizán. Huánuco. 45 p.

7. Foil, C. 1993. Dematofitosis. En: Craig Greene. Enfermedades infecciosas, perros y gatos. p 694-703. Ed. Interamericana McGraw- Hill. Mexico D.F.

8. Linton, AH.; W. Hugo; A. Russell. 1988. Disinfection in veterinary and farm animal practice. $p$ 20-23. Blackwell Scientific Publications. Oxford.
9. Litter, M. 1992. Compendio de farmacología. Ed. El Ateneo. Buenos Aires. 932 p.

10. Merianos, J. 1991. Quaternary ammonium antimicrobial compounds. En: Disinfection, sterilization and preservation. $4^{\text {th }}$ ed. Chapter XIII. Lea \& Fabiger. Philadelphia.

11. Schilling, P. 1984. Temas seleccionados sobre medicina de animales de laboratorio: el cobayo. Centro Panamericano de Fiebre Aftosa. Serie de Monografías Científicas y Técnicas $N^{\circ} 13$. Rio de Janeiro. $81 \mathrm{p}$. 